\title{
Cultural \& Climatic Actors: Shifting Roles of Architects and Practice
}

\author{
ASHLIE LATIOLAIS, AIA \\ University of Louisiana - Lafayette
}

PHANAT XANAMANE

Envision da Berry

Keywords: community, alternative methodologies, collaborative, practice.

As the skills required for creating architecture continue to broaden and deepen, integrating professional experience into architectural education will be increasingly necessary. This integration will create graduates that are more adaptable and versatile than through academic experience alone. Professional Practice discourse is an obvious venue for discussing and exploring the broader skills required for success and advancement in architectural practice, however, this paper entry discusses a shift of conventional practice to a practice that addresses community work - from product to processes - through a semester-long studio experience. The studio was dedicated to the students' professional development of social and environmental responsibility using a transdisciplinary and collaborative approach. The impacts of intersecting architectural practice and interdisciplinary collaborators with architectural education through community engagement dissolves the notion that these actors are mutually exclusive. Rather, what yielded is an inclusive approach to creating environments that are more socially conscious; benefitting both the students and community patrons.

The year 2020 has exacerbated systemic failures evident by continuing global socio-political unrest, worsening climate change events, and the COVID-19 pandemic. Though discussion around these vulnerabilities have been in focus for the past decade, the urgent call for architects to rethink their roles and methods, at all levels, is imperative. Architect and urban designer, Brian McGrath states,

"Architecture will only grow in importance, not in catching the latest wave of the globalization of data and capital, but in creating environments for making a place that is socially equitable and ecologically sustainable."

This call for reexamination is especially relevant when mitigating the impacts to the most vulnerable communities through a range of project types, from the scale of a city to the scale of an art installation. Public artist, Mary Miss, places emphasis on this stance in her statement,

\begin{abstract}
"The path to meaningful action is forged through a long-term process of relationship building... Facing an intractable problem like climate change can seem overwhelming. By focusing communities directly on local impacts and innovative solutions, we are helping to move the needle."
\end{abstract}

The education of an architect is fertile territory to forge new ways of integrating practice-based experience to aid in developing long-term relationships with communities. Architecture students should be taught the tools, rather than the outputs, to deepen their understanding of project sites as part of complex urban-natural ecosystems. With such tools, the community-sensitive architect can garner skills to interject with good design and adapt programs that have relevant social, cultural, and environmental implications for the communities in which they work. In addition to working alongside community members and stakeholders, a studio, in particular the one being discussed here, could be a model that reimagines how an architectural office environment could counter the "conventional" with a more "collaborative" type of practice through the emphasis on the "processes," rather than the products it provides.

\section{THE QUESTIONS}

This paper examines new methods within architectural education which can influence future modes of practice that encourage strengthening strategic partnerships with a community. The concepts for such practice are viewed through the lens of a semester-long Masters of Architecture graduate studio at the University of Louisiana Lafayette School of Architecture and Design. The studio's primary objective was prompted by a desire expressed by the American Institute of Architects Blueprint for Better Campaign, "...the public isn't always aware of what architects do or how their work affects society. The truth is, in partnership with their clients and communities, architects plant the seeds that blossom into stronger communities." The studio strived to flip the script, meaning, to bring the emerging architects out of the studio and into the community in which they would directly impact. Generally, initial student site visits yield bland, superficial readings and miss out of the usually very nuanced community dynamics. Too often are educational opportunities separated from immediate and physical interaction through site, communities, 


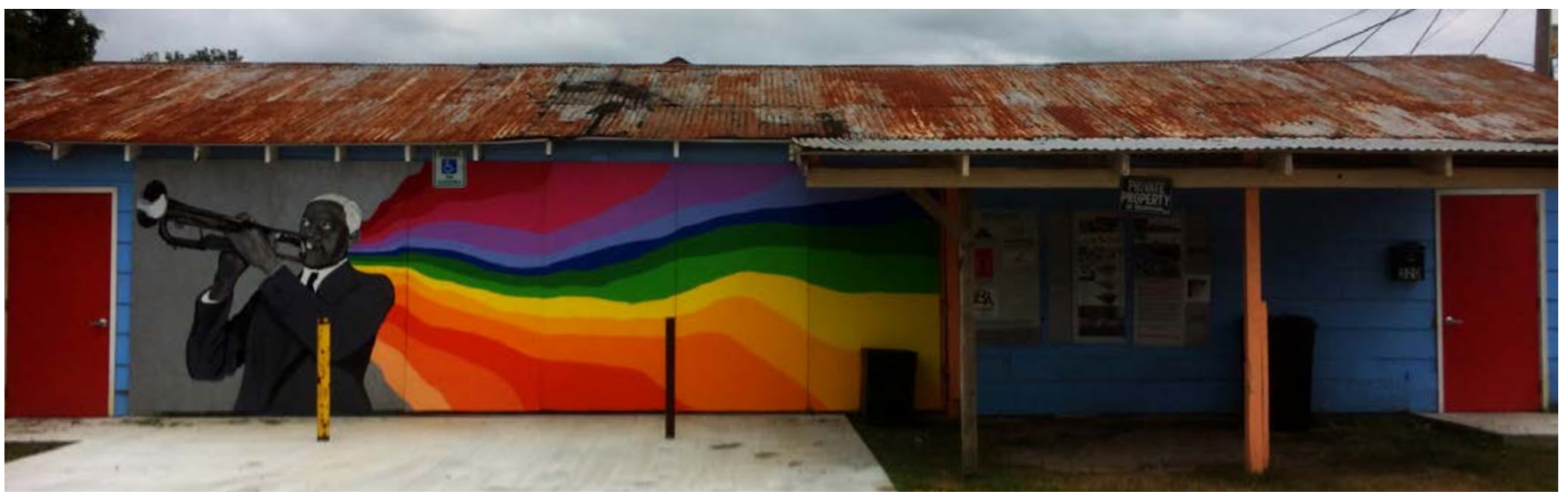

Figure 1. Bunk Johnson Mural at da Berry Fresh Market. Credit: Envision da Berry.

and / or clients that give access to fine-grain socio-cultural details of a place. Therefore, to question not only the roles but processes of practicing architects can directly impact the new skills learned within architectural education. This skill or tool-based learning requires the students to synthesize human interaction with the built environment and integrate their research and on-site experiences into their design proposals.

In order to successfully tackle problematic norms found in traditional architectural practices in the turn of the 21st century, the studio identified four traditional deliverables and offer proposed alternatives that could potentially achieve a more relevant architectural practice: 1 ) The static rigid masterplan product versus a framework for instituting actionable processes impacting the local built environment, 2) the formal community charette versus informal direct local action and engagement, 3) quick turnaround proposals versus building a timeline of institutional presence and acquired trust, and 4) the singular solution versus multi-scaler and transdisciplinary approaches that broaden the scope of inquiry while expanding the network of resources for the community.

The image in Figure 1 is the Bunk Johnston mural on the facade of Da Berry Fresh Market in New Iberia, Louisiana which sets the stage for this studio and testing of this kind of design practice. Quick and immediate renovations like the mural here gives new life and hope to a crumbling context. However, the mural alone can not solve systemic community problems with a single act. Communities like New Iberia's underserved West End District are where these questions posed by the studio began. Questions about the products that architects supply - the rigid, dust-collecting master plan, versus, a more active solution, through tangible public processes that strives to shift the inequality presented from the economically and politically degraded context. Further goals aim for architects to deploy tangible and more sustained design engagement in contrast to a one-time design charette, build strategic partnerships creating trust and long-term institutional presence, and foster transdisciplinary collaboration to further the reach of the work.

\section{METHODOLOGIES}

The studio approach relies on a definition of "collaborative practice" which alludes to a more engaged design process with focus on community, local economy, and urban actors. This collaborative practice is explored through a partnership with community not-for-profit organization "Envision da Berry" (EdB) which has worked in the small city of New Iberia, Louisiana (population 30,000) since 2011. Before entering the nuances of the partnership, a clearer picture of the specific site and why it may be called "under-served" shall be presented. The context and ecology of New Iberia's West End is crucial to understanding its socio-economic roots.

New Iberia is the parish seat of Iberia Parish, located along the coast of southern Louisiana. The city is identified as part of the Gulf of Mexico Coastal Region. This region is especially susceptible to impending climatic conditions such as coastal erosion, potential hurricane damage zones, and flooding. New Iberia's West End neighborhood, the once thriving commercial and cultural hub for the African-American community prior to desegregation, has witnessed more recent social, cultural, and economic decline. A look into the history and demographics of New Iberia reveals economic disjunction in architectural and master planning investment for communities like the West End. Demographics comparing the West End to other parts of the city reveal economic disparity in the past decade leading to a devastating deterioration of the neighborhood's urban fabric and loss of collective memory of the place. This once vibrant working-class area has been torn apart by crime, addiction, violence, and poverty. Comprising three census tracts, the West End is a predominantly African-American population and has roughly 9,000 residents, $30 \%$ of whom are living below the poverty line. For comparison, the 2017 US Census Small Area Income and Poverty Level Data shows the nation's poverty rate at $13.4 \%$, the state of Louisiana at 


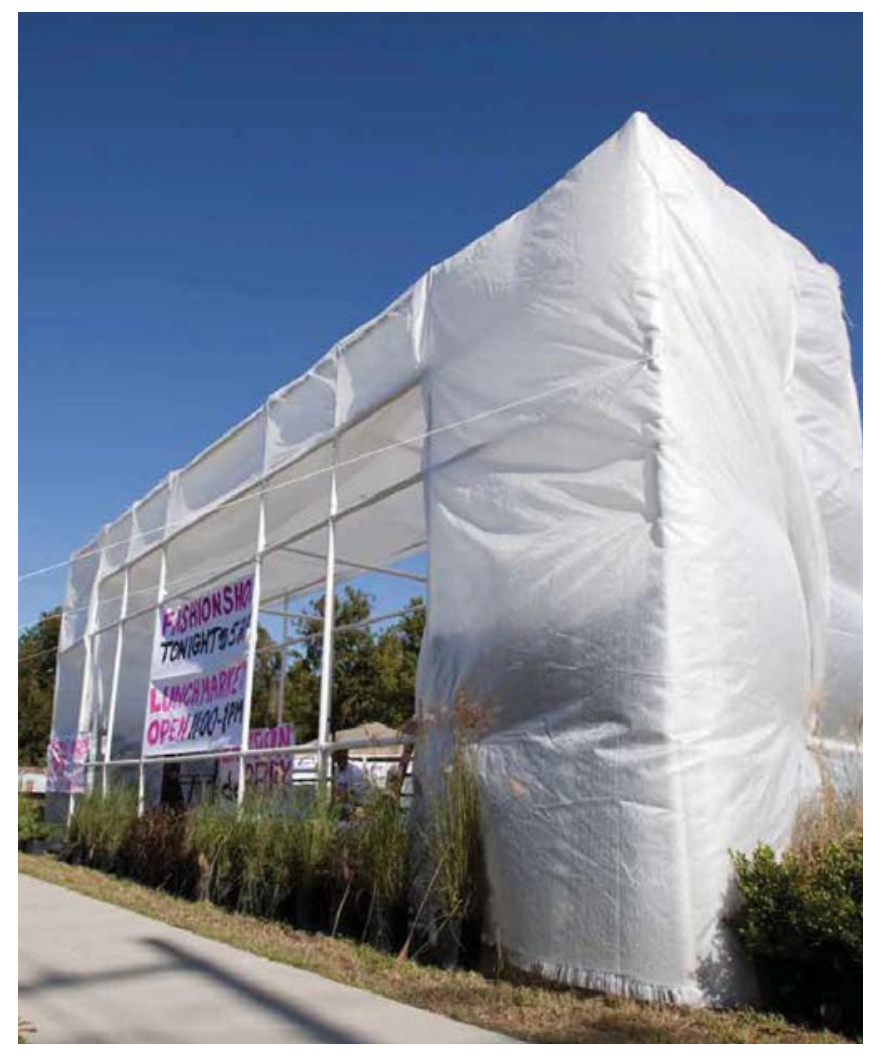

Figure 2. 2011 West End Installations. Envision da Berry.

19.6\%, and Iberia Parish's rate at 23.8\%. The West End shows an alarming $30 \%$ rate.

The graduate studio adopted a site and adaptive reuse program defined as a SNAP-approved, for-profit food retail market, Da Berry Fresh Market, located in the heart of the West End Cultural and Historic District. The market is the culmination of EdB's consistent long-term community based visioning process. EdB seeks to upgrade and expand this existing endeavor. This begins a discussion of a shift from conventional practice to a practice that targets more immediate cultural need. Strategies of including transdisciplinary figures into the studio conversation allowed for the students to have more thorough perspectives about the community and questions at play.

Insights into the local community context was imperative to the success of the studio's relationship to the place. Phanat Xanamane, served as a co-instructor for the studio and as an intermediary between studio, community, and client. This beneficial partnership of the studio gave access to a local individual, who was a co-founder of EdB, as well as stakeholder and native resident of the West End community. His background and professional experience as an urban designer working with ecologists at the Millbrook Institute for Ecosystems Studies and environmentally-conscious public artist Mary Miss brought forward unique intersections of knowledge into the studio's pedagogical framework. In EdB's 8-year history, Xanamane established a series of community initiatives and stakeholder relationships. Those relationships fostered cross-disciplinary guests to visit, offering discussions that would aid students. A peer question from the 2020 AIA / ASCA Intersections Symposium where this paper's preliminary form was presented underscores Xanamane's significance: "How crucial was Phanat's role as co-instructor of the studio?" His life-long personal ties to the community allowed for an intimate understanding of the social, economic and cultural fabric of the site. His presence was the cornerstone to this studio's trustful relationship that ensured continuity and longevity within the West End. Other studios may cultivate this kind of trust through institutional presence or strategic partnerships with individuals with strong personal ties within the community.

\section{RECALIBRATING THE TOOLS}

Prior to the nonprofit EdB's founding, the city went through planning and the public charette process at least three different times. Rather than create yet another top-down masterplan, EdB sought to make strategic temporary public space installations to initiate a tactical urbanism that would catalyze further engagement. In 2011, after a 5-week tem-

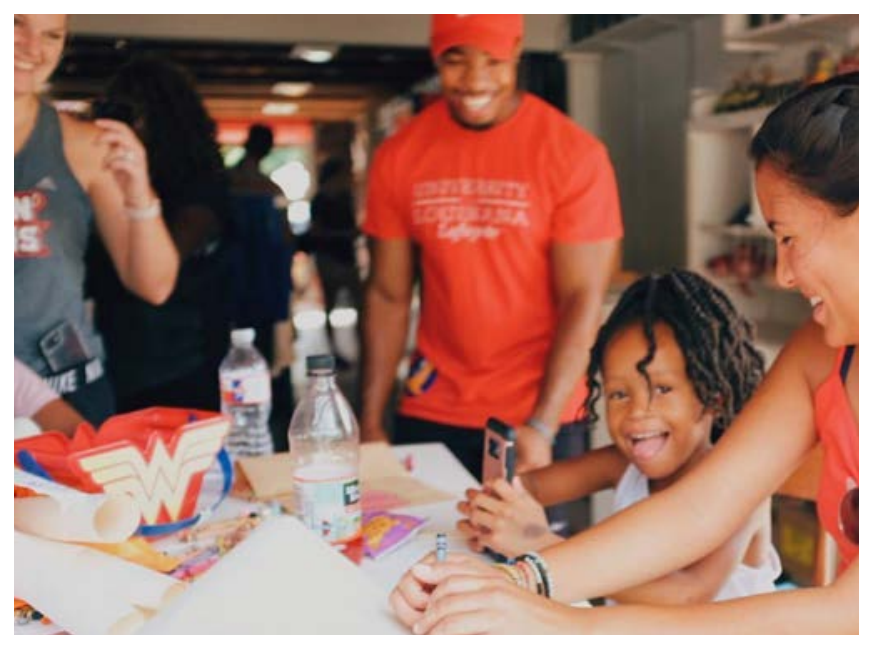

Figure 3. Redefined Charette: 2019 West End Brown Sugar Festival. Ashlie Latiolais.

porary installation, consistent dialogue through public art, performance, and social media campaign helped re-shape narratives about the West End (Figure 2). The diagram presents an alternative to a formal masterplan and instead, outlines a set of performative pieces to build connections in the community in various development sectors. Building upon this precedent of change and interaction, the studio, here, recalibrated its own tools for impact.

Beyond the regular site visits for documentation and remote analysis tools achieved through the internet, students were 


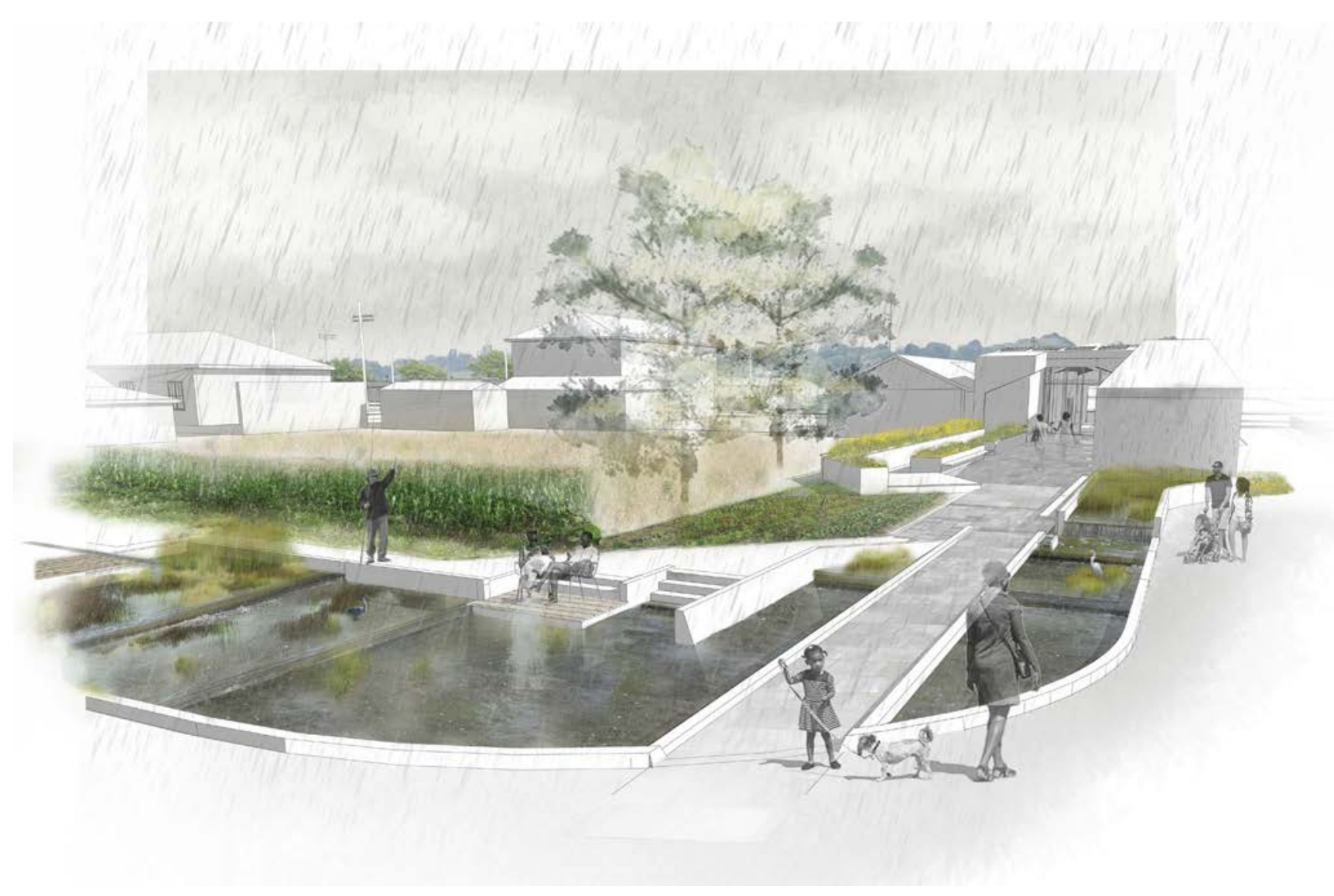

Figure 4. West End Weir System. Graduate Student Sean Siravo.

asked to engage and gather information in a very direct way with the community. This engagement served as a key strategy to understand the community on their own turf opposed to a formalized charette process organized by architects. One event that served as grounds for an informal engagement was when the students and instructors participated in the West End's "Brown Sugar Festival" (Figure 3). There, patrons and children were able to reveal the needs and wants of the community through informal conversation and activities while promoting mental health and well-being. Students observed as residents interacted with their own built environment: shopping, dancing, gathering, confabulating, eating, and living. The Festival served as a novel way to engage the community through an active local event, not created by us, but by them. The students took all of the experiences and verbal data back into the studio to synthesize the research and graphically convey the inequalities, fragmentation, and needs of the community, as well as the assets and idiosyncrasies (Figure 5). The studio instructors were keenly interested in the students' ideas and fostered them into mitigating essential architectural questions of today and tomorrow. The instructors supported students through this effort and the work that marked it. Interactions yielded beneficial positive experiences for residents and students and built a new trust that had not existed beforehand.
Interdisciplinary partners and stakeholders were also involved at several strategic points throughout the project. Investors, developers, council persons, psychologists, educators, non-profit directors, and scholars served as key influential resources. Carl Cooper Jr is the Market's current manager and is set to take full ownership of the market in the future after it grows out of its fledgling stages under the auspices of EdB. His input and vision for the space that serves this community was essential for students to understand the basic needs of the project's program. Beyond the immediate client's program needs other conversations with cross-disciplinary stakeholders in the market and the West End community were invited to inform the process. Investor David Levy and architect / developer Barry Broussard lended their perspectives offering their phased approach strategies toward investments. Dr. Caryn Winters, a former EdB board member and PhD in Mass Communication, prepared students for calling upon the expertise of the residents through culturally sensitive training and listening. Lorna Bourg and Denise Galatas with the notfor-profit organization, Southern Mutual Help Association that has accomplished work in the West End and other distressed communities for decades, spoke with students on the systemic racial and cultural issues embedded in the West End. The studio created anti-oppression toolkits where "call-in" versus "call-out" strategies utilized knowledge, assessment, 

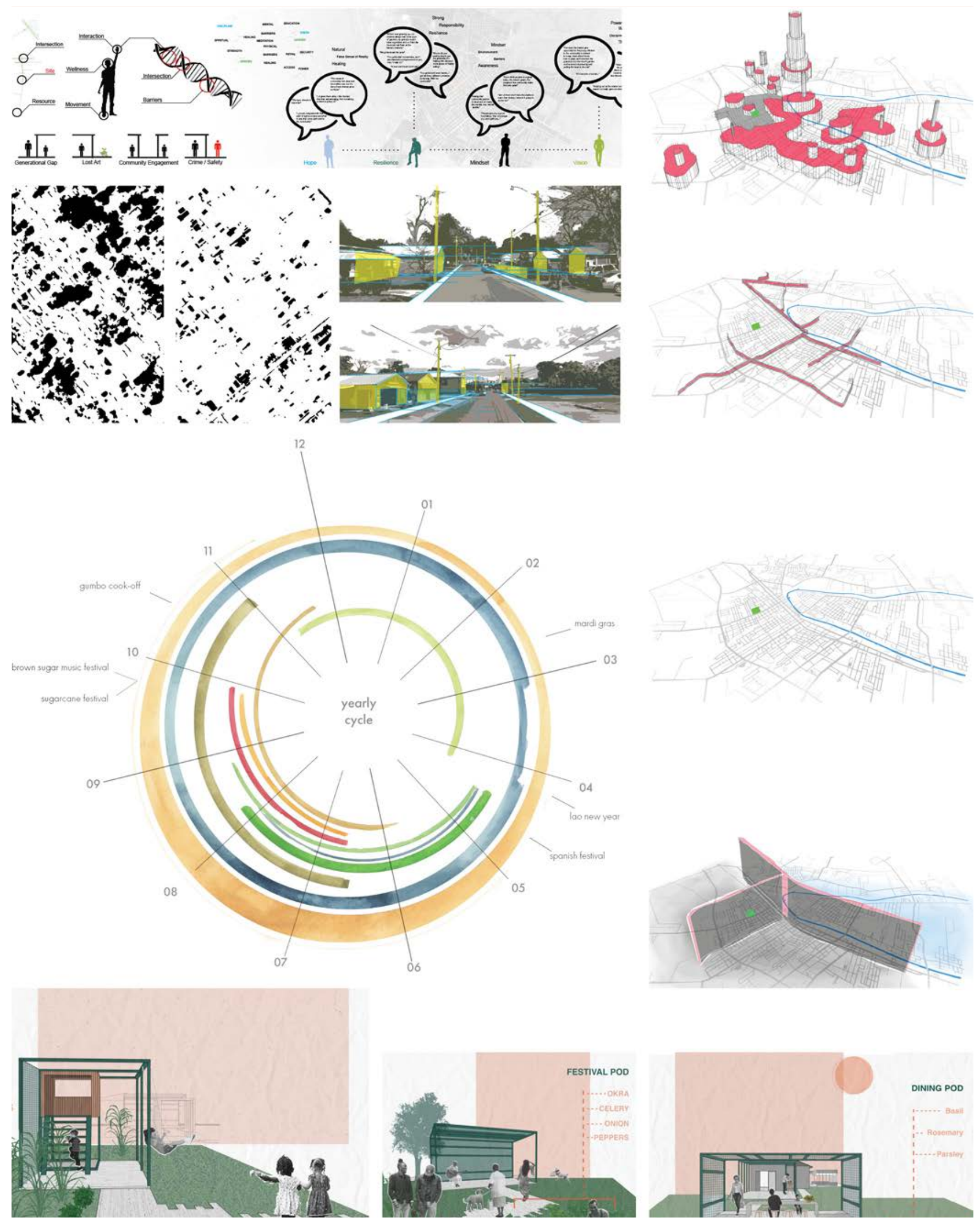


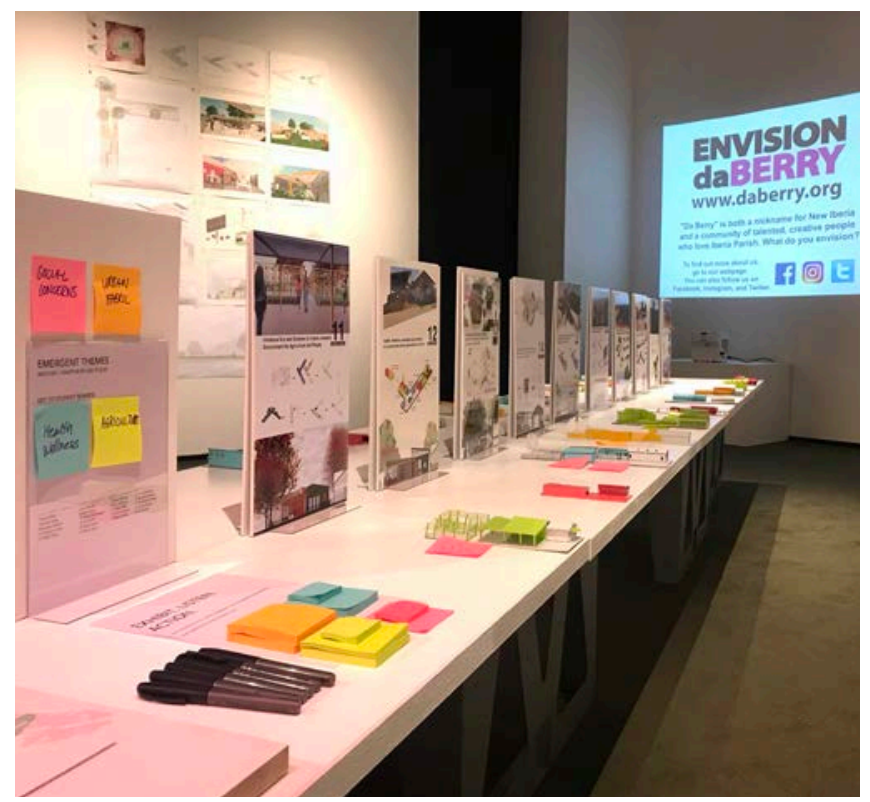

Figure 6. UL Lafayette Fletcher Hall Gallery. Ashlie Latiolais.

acceptance, and listening to reach compassionate communication within this community.

Four themes emerged from the student's research and engagement: Heath and Wellness, Agriculture, Social Concerns and issues of the Urban Fabric. All student proposals effectively encompassed one or more of the themes. The most successful students integrated all themes by not only demonstrating an understanding of the place culturally with sensitivity to its social needs, but also, environmentally. This student's proposal, pictured here, brought together rainwater harvesting and experiential weir systems into the site to harness the social and environmental interactions while being economically conscious of the agricultural program's demand for water irrigation. (Figure 4, above). The integration of these themes launched the trajectory of the studio's processes, and ultimately, established an open-source tool for furthering community interaction.

\section{A NEW PROCESS}

In addition to phased master planning drawings and details, the studio, most importantly, created a traveling exhibition device (Figure 6). The intention of this device is to be used extensively by the public as an interactive tool for conversation and community-based modeling. The first display was for final studio reviews where outside review critics could comment and discuss the very things discussed in this paper. As a way to start to frame an on-going conversation with a range of different audiences, a color-code system was devised using blue, pink, green, and gold representing the themes of the project foci. Blue denoted projects that addressed mental health and wellness, pink for larger social systemic issues, green, rightfully so, denoted agricultural focused projects, and gold for urban / infrastructural interventions. Students painted scaled-models of their proposed design accordingly. Then, the work was exhibited at the University of Louisiana's School of Architecture and Design Fletcher Hall Gallery.

When thinking about an open source tool, the accessibility of the information must maintain a level of inclusivity for the reader (that may not have training in design or architecture). Architects must be sensitive to the visualization of this information when presenting it to the public in which it directly affects. Visualizations also give the intentions of the project increased public credibility. Projects employing sensitive processes as related to planning efforts have later reported increased levels of clarity between stakeholders in terms of desired outcome and overall direction. Therefore, the studio began pairing the images with an active tactile tool, such as drawings plus physical models, for interaction to further convey scale, impact and materiality to the community and stakeholders. Although we have critiqued the traditional master plan, these drawings are still necessary to visualize the larger dream. However, once again, coupling these drawings with additional and alternate views (Figure 7, right) to describe the components is valuable to the public. It allows them to achieve small components over time rather than large scale, completed visions. These drawings intended to provide immediate information that balances the technical and the poetic.

\section{POST-STUDIO ACTION}

In the following Spring semester, after the studio concluded, Xanamane taught as a visiting artist at the Hilliard Art Museum on the UL Lafayette campus. The studio's traveling exhibition model became part of an interactive urban planning

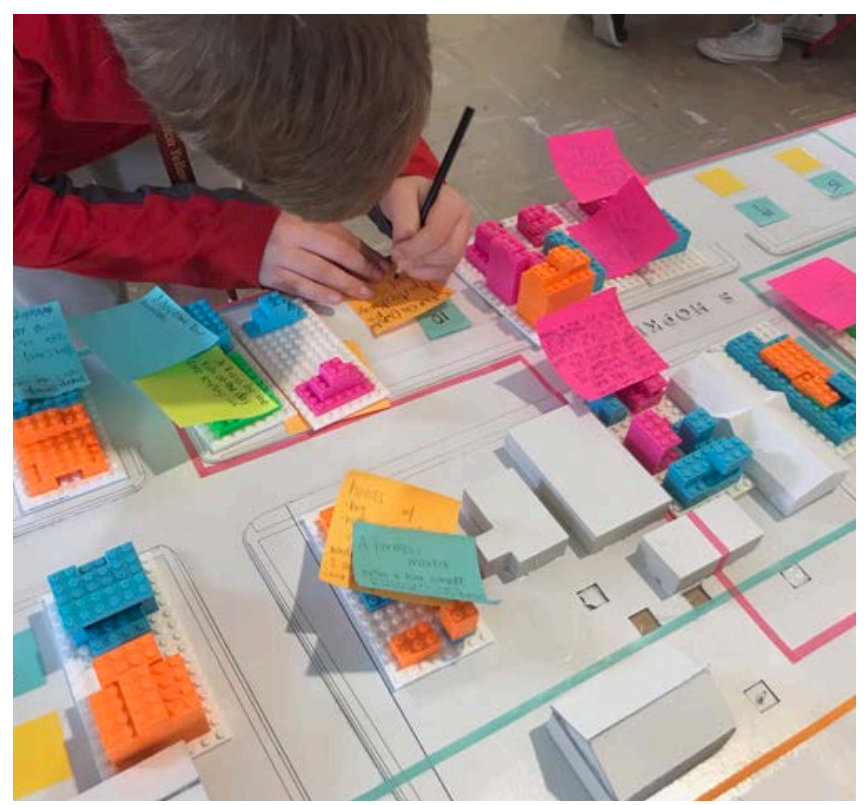

Figure 8. Open Source Exhibition Tool. Phanat Xanamane. 


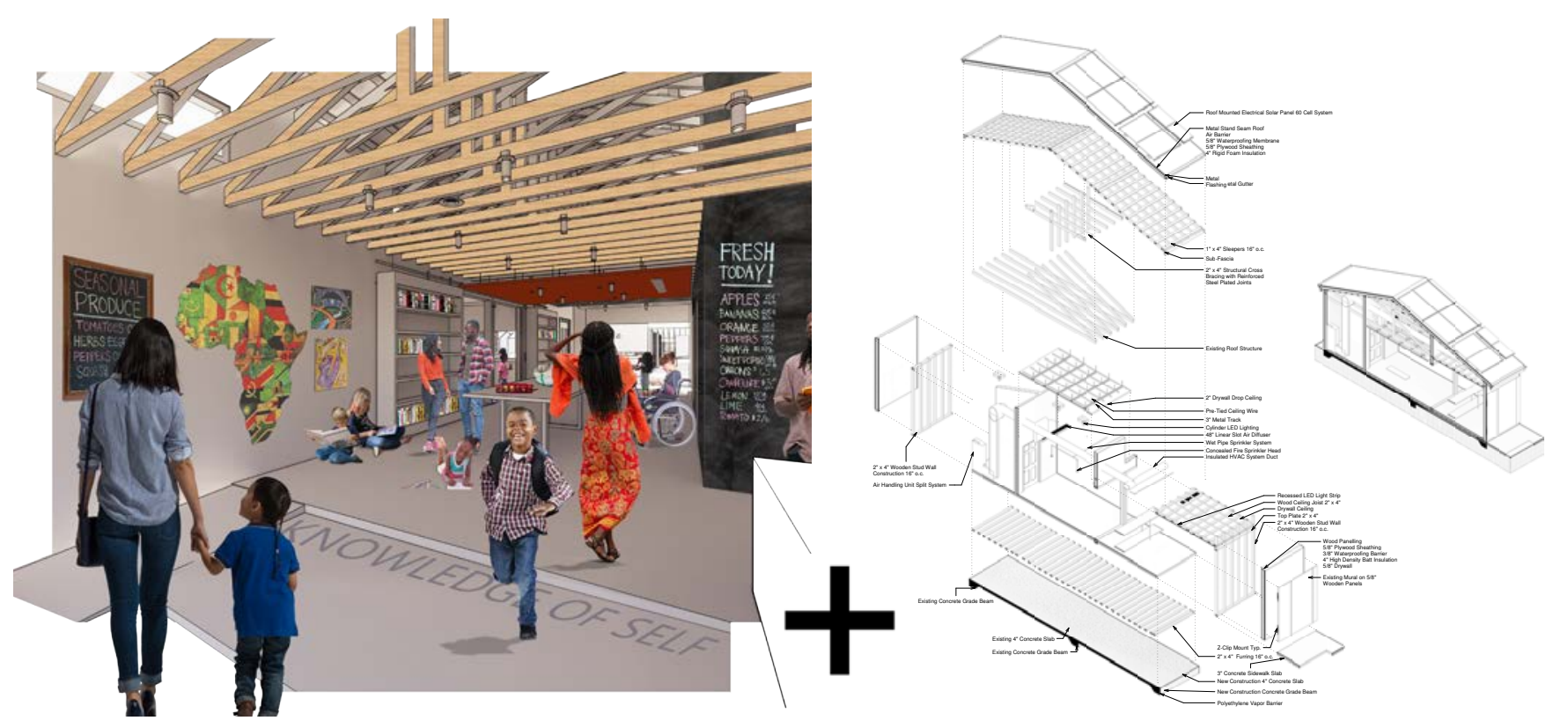

Figure 7. Pairing Visualizations. Graduate Student David Allen.

installation: "Box City" by sculptor Robert Tannen. Tannen's boxes and other durable sculptures at various scales were meant to be publicly interactive models for an imaginary "city." His installation was an inspiring tool for non-architecture students to understand scale, planning, defining and responding to a community's needs. Small workbooks were created to assist in teaching during tours of the installation which ended with students working with the Studio model.

Interactive lego tools were added to the site model (Figure 8 , left). The four themes (as defined by the studio) correlated to sticky notes and lego tools. Persons of all ages could comment and interact with the tool in a very accessible, informal, unintimidating, and playful way. K-12 school programs within the community made field trips to the Hilliard Art Museum in Lafayette, La - the second location of the exhibit. Museum visitors created various built environment scenarios for the West End. This proved as a great test dry-run before the model would eventually go to the market in New Iberia in the late Spring 2020. Unfortunately, the COVID-19 pandemic hit the world. Plans to open the exhibit back to the community in which it originated - the West End are currently on hold. Eventually, this final exhibition model will serve as an opensource tool to invite the public to collaborate with the goal that residents and stakeholders join in the process. The participatory model could be a helpful tool for residents of the neighborhood to gain support and further buy-in. Creating more accessible and tangible design tools for the community should be a priority for all community driven studios.

\section{IMPACT ASSESSMENT}

Now, one year later, it's relevant to reflect on the sustained impacts on this community. As most studio projects terminate at the end of a quarter or semester, this work is a piece of EdB's larger ten year commitment strategy. The studio's active performative processes instigated a new hope for the West End. The four initial questions from the studio established a level of engagement that the community respected and achieved action and equated to real dollars funded for further projects within the West End. The tools helped inform the process and the process fueled the work. This reciprocal relationship solidified the role of architects (and architectural students) to be integral players consistently and effectively.

Interrogating the dated models of practice redefined and reshaped the architecture student, a break from the master builder or top-down approach. Direct engagement proved to be successful when integrated into existing community networks and events. Valuable services for the community were also gleaned, such as the ability to see consistent value in architects work to manifest community vision and create opportunities for self / community reflection.

This work contributes directly to the greater understanding of the role of professional architects for all key participants - the architecture students, project partners and stakeholders, and the community. Architects can perform a more important role by connecting cross-disciplinary views and community expertise attained through direct public engagement to inform their approach towards design in underserved communities. The resulting work from students demonstrated multi-scalar approaches to the microcosm of cultural climatic issues calls for a practice that discusses the climate action needed to address cultural inequalities. 
Taking cue from the 2020 Intersections Symposium call for proposals, "How can architects help foster and realize community-based visions of equitable development and climate responsive design?" From product to process, from transactional to transformative, and we (as a studio) listened. Countering conventional practice became a clear choice when designing impactful interventions in the heart of the West End; an intentional re-alignment to a process that usually leaves communities lacking resources to take urgent action that will catalyze effective change.

In conclusion, the studio was dedicated to the students' professional development of social and environmental responsibility using a transdisciplinary and collaborative approach to: work in the public interest; understand the relationships between people, place, and context; improve the quality of life of the client and community; and design resilient proposals for the management and modification of the natural and built environment. Most importantly, the students' creative acts initiated dialogues in an under-served community and amplified the voices of community stakeholders through the collaboration with Envision da Berry and Da Berry Fresh Market. It's our hope to inspire a more profound impact, at a series of scales, within a community and re-think their methods to be more active performers within the built environment. This certainly holds true when considering futures of architectural practice focused upon community work. Every project, no matter the scale, should give voice and agency back to the communities in which they're cited. Architecture is a political act, architects must strive for a more inclusive process and deliverables that fosters more relevant and sensitive solutions.

\section{ENDNOTES}

1. McGrath, B. (2018). Architectural Localism as Damage Control in the Face of Globalism and Digitisation. Archit. Design, 88: 50-57. doi:10.1002/ad.2342.

2. Miss, Mary. "The path to meaningful action..." Message to Phanat Xanamane. 20 November 2019. E-mail.

3. AIA National. "Blueprint for Better Campaign". 8 September 2020. https:// www.aia.org/pages/89901-aia-public-awareness-campaign-2017-blueprint.

4. Small Area Income and Poverty Estimates (SAIPE), United States Census Bureau, 2018 www.census.gov/data-tools/demo/saipe/. Accessed 8 September 2020

5. C. S. Slotterback, "Public Involvement in Transportation Project Planning and Design," Journal of Architectural and Planning Research, vol. 27, no. 2, pp. 144-162, 2010.

6. 2020 AIA / ACSA Intersections Symposium "Call for Papers: Design for Climate Action: Intersections Symposium". 8 September 2020. https://www.acsa-arch $\mathrm{org} /$ conference/2020-intersections-symposium/call-for-submissions/. 